\title{
A novel synthetic test system for thyristor level in the converter valve of HVDC power transmission
}

\author{
Longchen Liu ${ }^{1}$, Ke Yue ${ }^{2}$, Lei Pang ${ }^{2}$, Xinghai Zhang ${ }^{1}$, Yawei Li ${ }^{1}$ and Qiaogen Zhang ${ }^{2}$ \\ ${ }^{1}$ State Grid Sichuan Electric Power Research Institute, 610072 Chengdu, China \\ ${ }^{2}$ School of Electrical Engineering, Xi'an Jiaotong University, 710049 Xi'an, China
}

\begin{abstract}
The converter valve is the core equipment in the HVDC power transmission system, a+-nd its performance has a direct effect on the reliability, stability and efficiency of the whole power system. As the basic unit of HVDC converter valve, the thyristor level needs to be test routinely in order to grasp the state of the converter valve equipment. Therefore, it is urgent to develop a novel synthetic test system for the thyristor level with thyristor control unit (TCU). However, currently there is no specific test scheme for the thyristor level of HVDC converter valve. In this paper, the synthetic test principle, content and methods for the thyristor level with TCU are presented based on the analysis of the thyristor reverse recovery characteristic and the IEC technology standard. And a transient highvoltage pulse is applied to the thyristor level during its reverse recovery period in order to test the characteristics of thyristor level. Then, the synthetic test system for the thyristor level is applied to the converter valve test of $\pm 800 \mathrm{kV}$ HVDC power transmission project, and the practical test result verifies the reasonability and validity of the proposed synthetic test system.
\end{abstract}

\section{Introduction}

As the core element of HVDC converter valve, thyristor is massively adopted to transmit electric power energy because of its high power capacity. The converter valve usually consists of a large number of thyristor levels, which are connected in series. Each thyristor level needs to be test routinely during the maintenance period of electrical equipment in order to make sure that their electrical properties and functions are in normal state. Considering the large number of thyristors, there is a heavy workload of thyristor level test. Therefore, it is important to develop a synthetic test system for thyristor level in HVDC converter valve.

As to electrical test of HVDC converter valve, IEC 60700-1-2008 and GB/T20992-2007 technology standard provide some relevant provisions $[1,2]$. However, these provisions mainly focus on the type test, such as dielectric test and operation test. Although these standards provide some general descriptions for routine test (for instance, the inspections of wiring, equalizer circuit parameters and withstand voltage), corresponding scheme and specific content of judgement methods in the routine test are scarcely mentioned. To date, some researchers introduced and studied type test and operation test of the converter valve. Ding [3] and Luo et al. [4] studied type test of converter valve and provided specific experiment protocol, requirement and improvement plan [5]. Zha et al. [6, 7] and $\mathrm{Hu}$ et al. [8] studied operation test under various actual operating conditions. However, studies on in-situ routine test for thyristor level of converter valve are rare. Zha et al. [9] studied routine test and proposed a thyristor level unit routine test program, but failed to investigate the TCU testing. Some international companies developed comprehensive testing devices for in-situ synthetic test of thyristor level, for example ABB, Siemens and Alstom. Yet, the domestic standard of relevant routine test for converter valve products is still in preliminary stage [10-12]. Therefore, it is necessary to establish a routine synthetic test system for thyristor level, which can ensure the performance of thyristor level and provide technical support for the operation and maintenance of HVDC converter valve.

Based on the analysis of the electrical principle and failure mode of thyristor level unit, this paper proposed a synthetic test scheme for in-situ routine test, and the synthetic test system is applied to the converter valve test of a practical $\pm 800 \mathrm{kV}$ HVDC power project.

\section{Electrical structure and principles of thyristor level}

The converter valve is arranged in modules, which contains a large number of thyristor level units connected in series. As shown in Figure 1, thyristor level unit with TCU is the basic structural unit in converter valve, which consists of thyristor, damping circuit $\left(R_{1-6}, C_{\mathrm{c} 1}, C_{\mathrm{c} 2}\right)$, equalizing circuit $\left(R_{41}, R_{42}\right)$, thyristor control unit (TCU) and energy storage circuit for TCU $\left(C_{3}, R_{3}\right)$. 


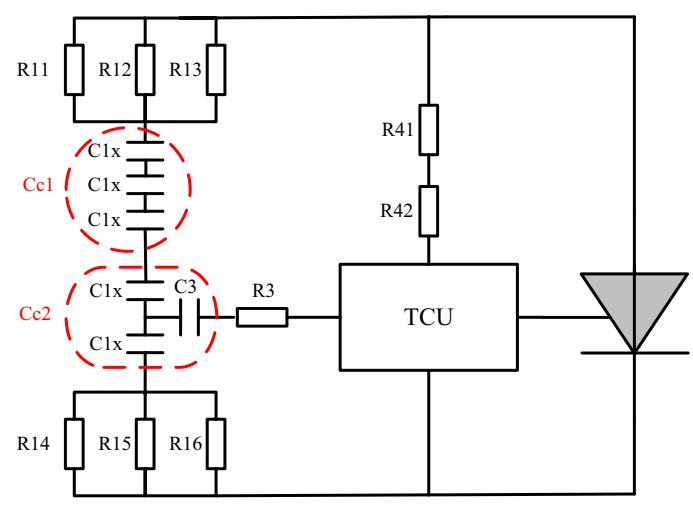

Figure 1. Electrical diagram of thyristor level with TCU.

Under the condition of inductive loads, reverse recovery overvoltage would be generated across the thyristor during the turn off process, which even exceeds the reverse repeat peak voltage of the thyristor and breaks the thyristor. Therefore, a parallel damping circuit is usually connected to the thyristor to absorb the reverse recovery charge and prevent the voltage overshot during the turn off process, which is shown in Fig. 1.

TCU is the core component in thyristor level unit. Thyristor level unit is at a high potential, whereas the control module of the converter valve is at ground potential. Therefore, an electric isolation is required in the transmission of trigger signal. Optoelectronic isolation has been widely applied in electric isolation. Valve control unit (VCU) at ground potential converts the electrical trigger pulse, which is produced by the control module of the converter valve, into optical pulse and transmits this optical pulse to TCU by the optical fiber. TCU reconverts the optical pulse into electrical pulse, and transmits this electrical pulse signal to the gate pole of the thyristor. Then the thyristor is triggered. Except the normal trigger function described above, TCU includes two protective trigger circuits: the protective firing (PF) circuit and the recovery protection (RP) circuit. The working voltage of TCU is obtained by coupling the voltage of thyristor level unit.

If the thyristor cannot be normally triggered, the forward voltage across the thyristor would continue to increase. In case that the forward voltage may exceed the rated value, PF circuit would send an emergency trigger pulse automatically in order to force the thyristor to be conducted, which avoids the thyristor being damaged. During the turn off process, TCU would detect the terminal voltage of the thyristor, and send an emergency trigger pulse to trigger the thyristor and prevent breaking if the disturbance voltage exceeds the rated value.

\section{Research and development of synthetic test system for thyristor level}

\subsection{Electrical structure of synthetic test system}

Figure 2 shows the structure and principle of the synthetic test system for thyristor level of HVDC converter valve. The synthetic test system is composed of the main circuit, control unit, communication module, peripheral equipment interface circuit and the corresponding power distribution protection module. As shown in Figure 2, the main circuit of synthetic test system includes three circuit modules: fundamental frequency $(50 \mathrm{~Hz})$ power supply module, high voltage impulse power supply module and high frequency sinusoidal wave signal generator, these three power modules can be switched by the time control of highvoltage relay. The electromagnetic interference (EMI) module in the figure is a filter, which is used to prevent electromagnetic interference.

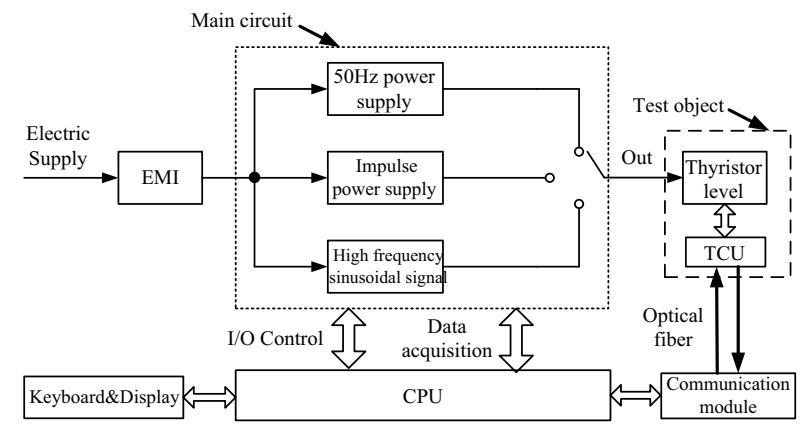

Figure 2. Diagram of test system for thyristor level of HVDC converter valve.

The electrical structure of high voltage impulse power supply module is shown in Figure 3. This power supply module consists of seven parts: a bidirectional thyristor $V_{1}$, a boost transformer $T_{2}$, a controllable rectifier $V_{2}$, a RLC discharge circuit, a power electronic switch $\left(\mathrm{V}_{3} \sim \mathrm{V}_{6}\right)$, a internal protection circuit $\left(\mathrm{V}_{7} \sim \mathrm{V}_{10}\right)$ and a driving circuit $\left(Q_{3}, Q_{4}\right)$. As shown in Figure 3(a), the switch $S_{2}$ is mainly used for switching power to different power modules; $\mathrm{R}_{1}$ and $R_{2}$ is the protection resistance; the energy storage capacitor $C_{1}$ is charged through the boost transformer $T_{2}$ in order to get a high voltage impulse; the output voltage can be adjusted through changing the $\mathrm{AC}$ positive and reverse conduction angle of the bidirectional thyristor $\mathrm{V}_{1}$, and the thyristor $\mathrm{V}_{1}$ must be triggered on zero by control unit $\mathrm{Q}_{2}$ to ensure the output waveform is a standard sine wave. In Figure 3(b), $\mathrm{C}_{1}$ is the energy storage capacity; $\mathrm{L}$ is the inductance of RLC oscillation circuit; $\mathrm{L}_{1}$ is used to adjust the impulse voltage waveform; $\mathrm{L}_{2}$ is a key part of the discharge circuit; $V_{3} \sim V_{6}$ is used as a forward switch; and $V_{7} \sim V_{10}$ is the switch of discharge circuit. And the energy of high voltage impulse can be released through the loop $V_{7} \sim V_{10}-R_{3}-R_{4}-V_{3} \sim V_{6}$.

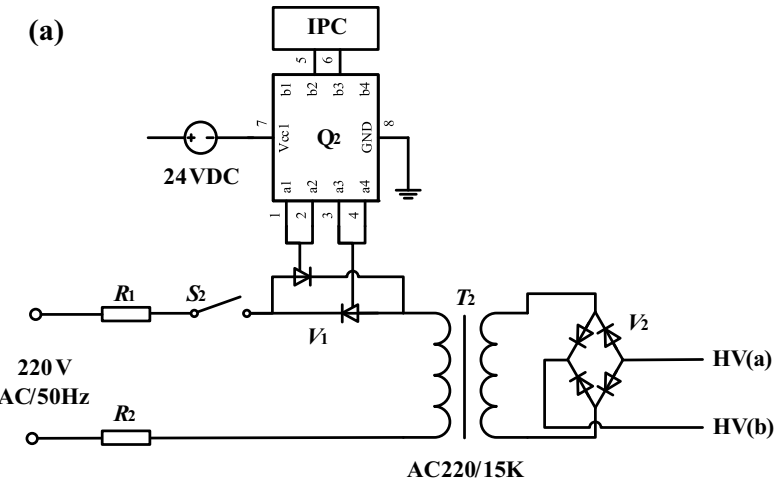

(a) High voltage rectifier circuit 


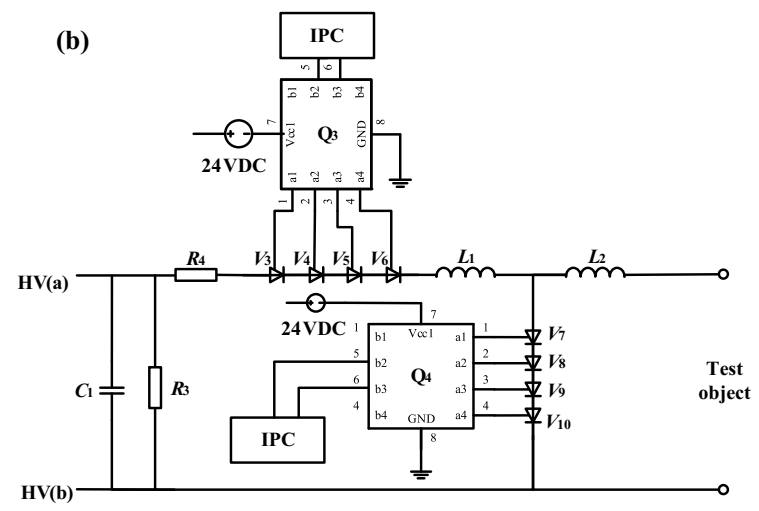

(b) High voltage impulse circuit

Figure 3. Electrical diagram of high voltage impulse power supply module.

\subsection{Synthetic test contents of thyristor level}

By analyzing common faults of thyristor level unit, a test scheme of in-situ synthetic test is developed on the basis of its failure modes. Combing the standard IEC 60700-1 and the working principle, the test projects for the in-situ synthetic test of the thyristor level unit are developed. Items of the routine synthetic test are shown in Table 1.

Table 1. Synthetic test items of the thyristor level.

\begin{tabular}{cc}
\hline Test items with low voltage & Test items with high voltage \\
\hline Impedance test & TCU protective function test \\
Firing test & Reverse test \\
\hline
\end{tabular}

\subsubsection{Impedance test}

Impedance test detects the short circuit or the open circuit within the voltage equalizing circuit and damping circuit. It is a low voltage test, the voltage of which does not reach thyristor turn on voltage, therefore the corresponding impedance is mainly refer to the impedance of capacitors and resistors within the equalizing and damping circuits.

The circuit diagram of impedance test is shown in Figure 4(a), where the voltages with different frequencies generated by the sine wave generator are imposed on thyristor level unit. The peak voltage and current across the thyristor are measured during the test, and the impedances of the circuit under different frequencies are calculated. The obtained impedance is compared with the threshold, therefore the conditions of resistors and capacitors in the thyristor level unit can be evaluated.

\subsubsection{Fire test}

Fire test detects whether TCU is able to respond properly to optical pulse signal and send a trigger pulse to the thyristor. The test circuit of fire test is shown in Figure 4(b), where AC circuit with power frequency applies a forward voltage to the thyristor, and the electronic power switch controls the phase angle.

\subsubsection{TCU protective function test}

Ensure the performance of thyristor under the following conditions: (I) the thyristor suffers from an overvoltage exceeding the designed voltage threshold; (II) the thyristor is subjected to a transient forward impulse during its turn off process, the TCU should be tested by the PF and RF tests. In this study, RP test includes PRL tests and PRH tests. The parameters of impulse voltage used for RP test are shown in Table 2. PRL test is performed during the reverse recovery period of the thyristor. After the thyristor regain its reverse blocking ability, PRH test is performed.

The test circuit of TCU protective function is shown in Figure 4(c). The AC circuit provides a normal forward voltage for the thyristor, and the impulse circuit generates a forward impulse voltage. The power electronic switch is able to forcedly cut off the on state current and control trigger phase angle. These three modules are putting into operation according to a predefined controlling sequence.

Table 2. Parameters of the RP test.

\begin{tabular}{ccc}
\hline Test project & Amplitude & Time \\
\hline RPL & $2 \mathrm{kV}$ & $\left(\mathrm{t}_{\mathrm{rr}}\right)_{\max }+50 \mu \mathrm{s}$ \\
$\mathrm{RPH}$ & $10 \mathrm{kV}$ & $1.2\left(\mathrm{t}_{\mathrm{rr}}\right)_{\max }$ \\
\hline
\end{tabular}

\subsubsection{Reverse test}

The blocking ability of the thyristor to reverse voltage can be evaluated through reverse test. The test circuit of reverse test is shown in Figure 4(d), where the impulse circuit provides a reverse voltage impulse, and the voltage divider is used to measure the impulse voltage.

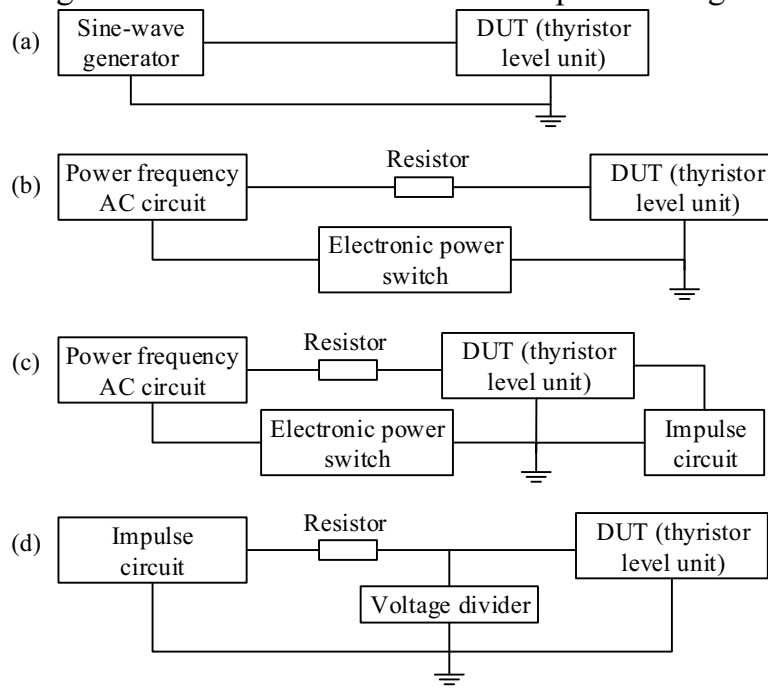

(a) Impedance test; (b) Fire test;

(c) TCU protective function test; (d) Reverse test

Figure 4. The synthetic test diagram of thyristor level.

\section{Application of synthetic test system for thyristor level}

The synthetic test system was applied to the in-situ test of the KGWF03-5000/ \pm 800 thyristor level in the converter value of HVDC power transmission. The acceptance 
standard and the interrelated technical regulations of the in-situ synthetic test are listed in Table 3, and the test results and analyses are presented as follows.

Table 3. Technical specifications of $\pm 800 \mathrm{kV}$ HVDC power transmission.

\begin{tabular}{cc}
\hline Test items & Acceptance criteria \\
\hline Impedance test & $110 \mathrm{~Hz}: 664 \sim 1727 \Omega$ \\
Firing test & $6000 \mathrm{~Hz}: 26 \sim 36 \Omega$ \\
& $\mathrm{U}_{\mathrm{th}}: 32 \pm 10 \mathrm{~V}$ \\
TCU protective function test & $\mathrm{U}_{\mathrm{PF}}: 8050 \sim 8500 \mathrm{~V}$ \\
& $\mathrm{U}_{\mathrm{RPL}}: 1475 \sim 1775 \mathrm{~V}$ \\
Reverse test & $\mathrm{U}_{\mathrm{RPH}}: 8050 \sim 8500 \mathrm{~V}$ \\
& $\mathrm{U}_{\mathrm{REV}}: 8040 \sim 8340 \mathrm{~V}$ \\
\hline
\end{tabular}

Figure 5 shows the impedance test waveform. The PRL and RPH test worked on frequencies of $110 \mathrm{~Hz}$ and $6 \mathrm{kHz}$ respectively. The peak voltage and current of the thyristor were measured during the tests, and then the impedance under each corresponding frequency was calculated. The impedances in PRL and PRH test were $685 \Omega$ and $29 \Omega$ respectively, which met the requirements of the technical specifications.
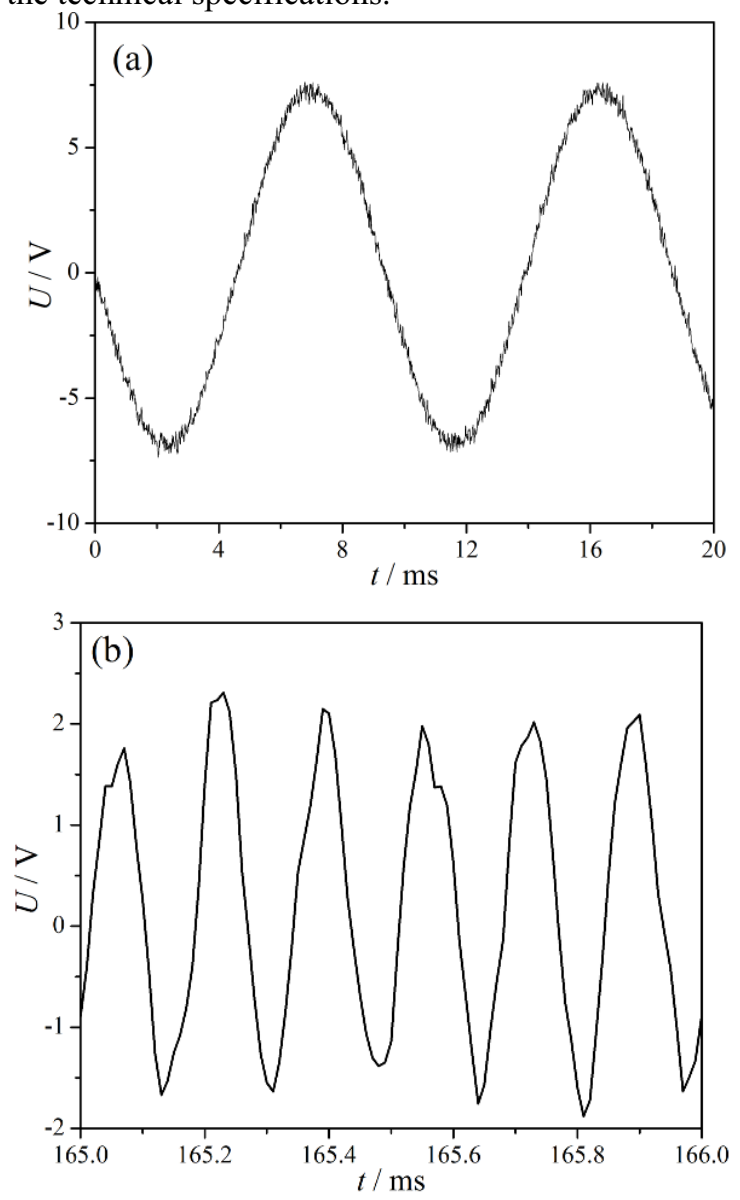

(a) $110 \mathrm{~Hz}$; (b) $6000 \mathrm{~Hz}$

Figure 5. The waveform of impedance test.

Figure 6 shows the waveform of the fire test. The thyristor level unit was imposed by a power frequency voltage. It can be found that TCU took the power and then triggered the thyristor. The measured voltage of the triggered thyristor was $35 \mathrm{~V}$, which met the demand of technical specifications.

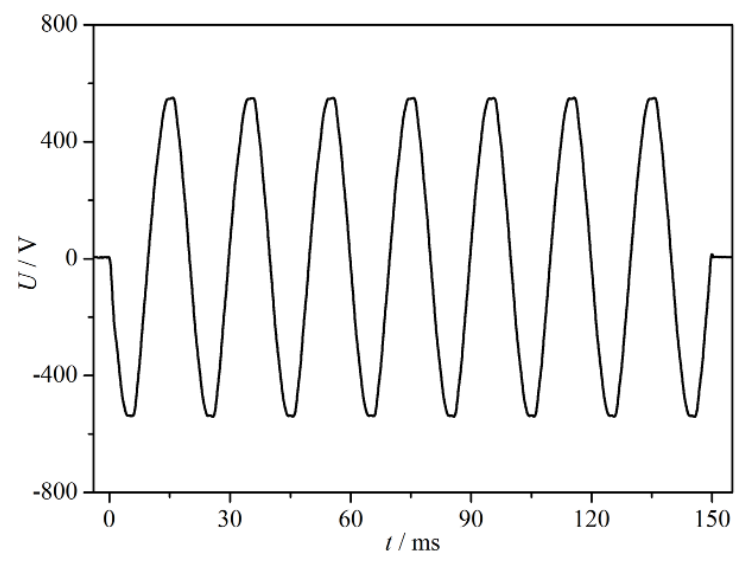

Figure 6. The waveform of fire test.

Figure 7(a) shows the waveform of the PF test. When the impulse voltage reaches the protection threshold of TCU, TCU will send an emergency pulse to trigger the thyristor. The peak value of forward voltage was measured to be $8067 \mathrm{~V}$ when the thyristor was triggered by TCU. Figure 7(b) and 7(c) show the waveforms of the RPL and RPH test respectively. A power frequency voltage was applied to the thyristor, and then the reverse voltage turned off the thyristor. During the reverse recovery process, a low voltage impulse was applied through the impulse circuit at $1050 \mu$ s later than the moment when the thyristor voltage began to reverse. This action threshold of TCU was $1475 \sim 1775 \mathrm{~V}$, and TCU operated when the impulse voltage was $1660 \mathrm{~V}$. Figure 7(c) shows the thyristor voltage waveform of the RPH test. A high impulse voltage was applied by the impulse circuit at $1200 \mu \mathrm{s}$ later than the moment when the thyristor voltage began to reverse. This action threshold of TCU is $8050 \sim 8500 \mathrm{~V}$, and TCU operated when the impulse voltage was $8099 \mathrm{~V}$. The TCU protective function met the technical requirements as expected.

Figure 8 shows the waveform of the reverse test. Reverse voltage impulse was imposed on the thyristor, and ensure that thyristor breakdown would not take place. The protective circuit released the energy of high voltage impulse and protected the thyristor. The voltage peak value of reverse impulse on the thyristor was measured to be $8290 \mathrm{~V}$. It was indicated that the reverse test passed.

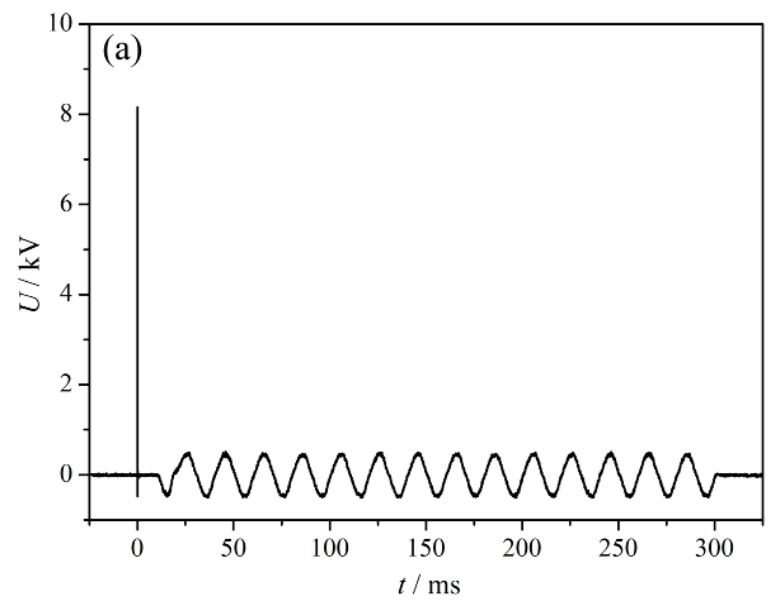



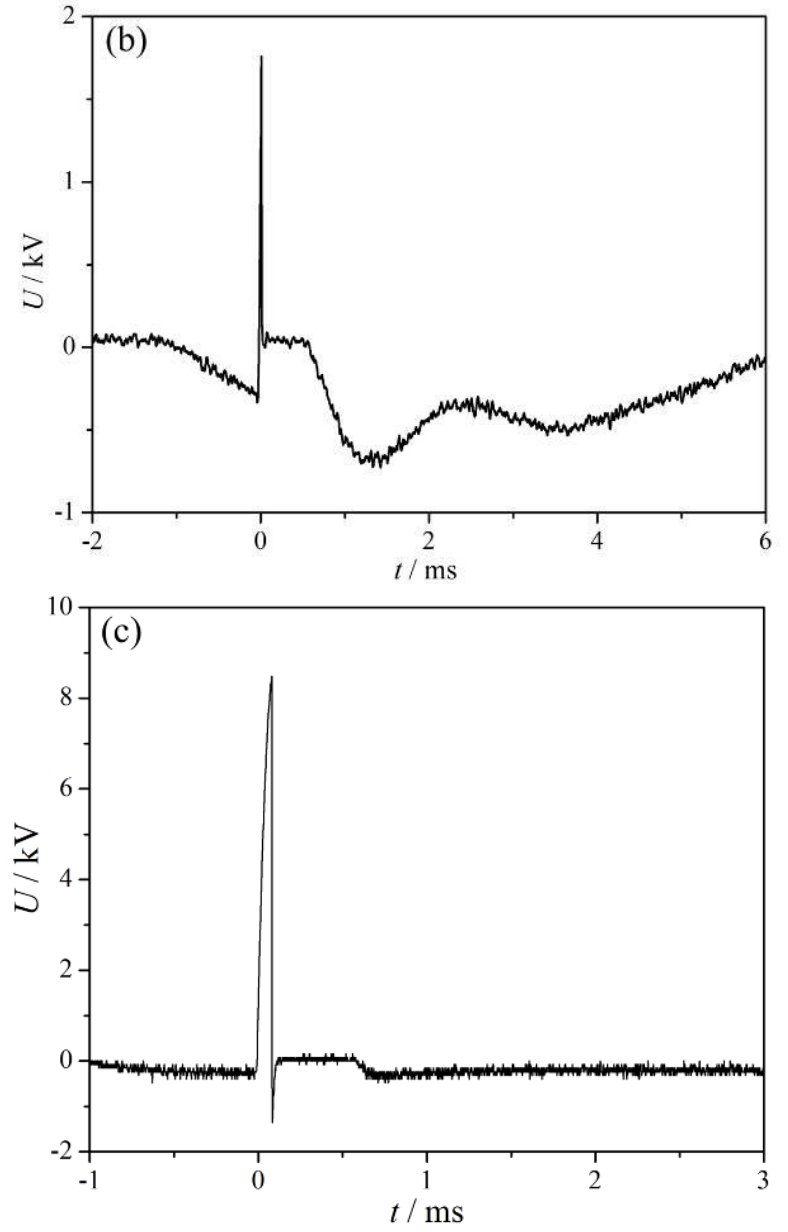

(a) PF test; (b) RPL test; (c) RPH test

Figure 7. The waveforms of TCU protective function test.

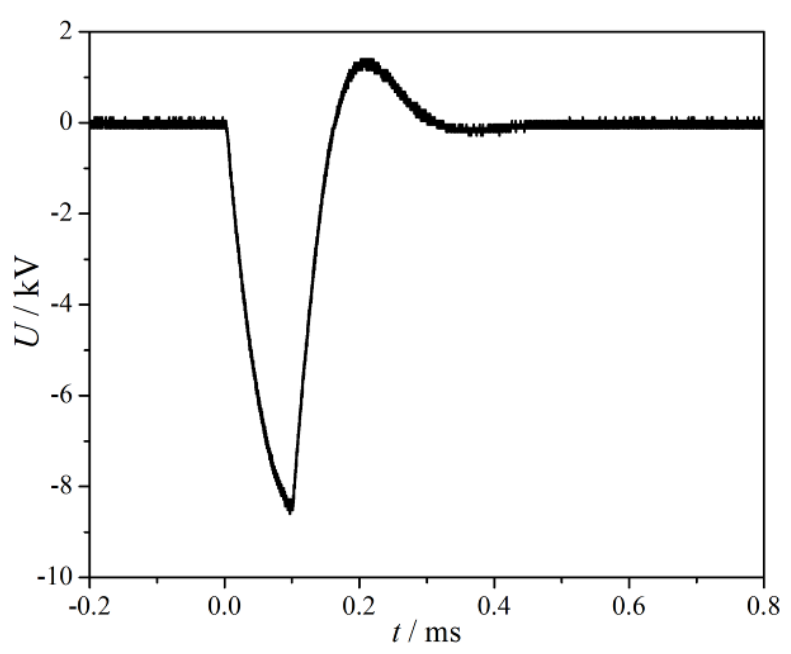

Figure 8. The waveform of reverse test.
By analyzing the test waveforms above, the thyristor level unit of the HVDC converter value met the technical requirements and all tests passed, which proved and verified the reasonability and validity of the proposed insitu synthetic test system and method.

\section{Conclusions}

In this paper, the in-situ synthetic test technology of thyristor level in HVDC converter valve was investigated. Through analyzing the structure and working principle of thyristor level in the converter valve, and combining with the technical standards IEC 60700-1-2008, the synthetic test content and method for the thyristor level with TCU was proposed. And the in-situ test of thyristor level included impedance test, fire test, TCU protective function test and reverse test. The in-situ synthetic test system was developed and applied to the thyristor level test of $\pm 800 \mathrm{kV}$ HVDC converter valve in order to verify the rationality and validity of this test system and method. The test waveforms indicated the performance of thyristor level in the converter valve met the technical requirements of HVDC power transmission. The results showed that this test system and method was reasonable, and satisfied the demand of engineering applications.

\section{References}

1. IEC60700-1. Geneva: International Electrotechnical Commission (2008)

2. GB/T 20992-2007. Chinese standard SN for books. Beijing: China Standard Press (2007)

3. Y. G. Ding, Electric Power Construction, 29, 2 (2008)

4. X. Luo, G. F. Tang, Power System Technology, 34, $5(2010)$

5. E. Nho, B. Han, Y. Chung, IEEE Transaction on power delivery, 27, 2 (2012)

6. K. P. Zha, J. L. Wen, Power System Technology, 34, $12(2010)$

7. K. P. Zha, C. Gao, Power System Technology, 36, 2 (2000)

8. Z. L. Hu, F. Xu, High Voltage Apparatus, 49, 4 (2013)

9. K. P. Zha, G. Y. Wang, High Voltage Engineering, 38, 11 (2012)

10. T. Bauer, H. P. Lips, IEEE Transaction on Power Delivery, 12, 3 (1997)

11. E. Nho, B. Han, Y. Chung, IEEE Transaction on Power Electronics, 29, 7 (2014)

12. G. F. Tang, K. P. Zha, IEEE Transaction on power delivery, 28, 3 (2013) 